\title{
Sistem Kontrol Sirkulasi dan Deteksi Kekeruhan Air Berbasis Mikrokontroler
}

\author{
Akuwan Saleh, I Gede Puja Astawa \\ Jurusan Teknik Telekomunikasi, Politeknik Elektronika Negeri Surabaya \\ Institut Teknologi Sepuluh Nopember (ITS), Surabaya, Indonesia \\ Kampus ITS Keputih Sukolilo, Surabaya 60111 \\ Telp. +62 (31) $5947280 \quad$ Fax +62 (31) 5946114 \\ E-mail: akuwan@eepis-its.edu,puja@eepis-its.edu
}

\begin{abstract}
ABSTRAK
Salah satu kendala yang dihadapi dalam usaha pemeliharaan ikan adalah kondisi air yang buruk sehingga banyak ikan yang mati. Untuk menjaga air agar tetap jernih diperlukan pengawasan intensif serta diperlukan metode yang mampu mengontrol sirkulasi air dengan baik.

Pada paper ini dibuat sistem kontrol sirkulasi dan deteksi kekeruhan air yang telah diimplementasikan pada kolam/aquarium pemeliharaan ikan. Dengan menggunakan sensor, kondisi air ketika keruh dapat diketahui dan akan diganti secara otomatis dengan air yang jernih oleh mikrokontroler sebagai pengendali. Sensor kekeruhan air menggunakan LDR, lampu TL sebagai penerang agar sensor dapat mendeteksi perubahan kondisi air.

Data dari sensor diolah mikrokontroler dan dihitung menggunakan logika fuzzy untuk menentukan kondisi air keruh, sedang dan jernih yang ditampilkan pada LCD. Selanjutnya mikrokontroler memberikan instruksi pada katup yang terdapat pada kolam/aquarium untuk membuka atau menutup untuk melakukan proses sirkulasi air. Percobaan yang telah dilakukan menggunakan aquarium ukuran 30x20x30 Cm, sample air yang digunakan adalah air jernih dan diberi noda untuk mendapatkan 3 kondisi. Hasil yang diperoleh, apabila kondisi air keruh proses pengurasan dilakukan 3 kali lebih, kondisi sedang dilakukan antara 1 sampai 2 kali, kondisi jernih tidak dilakukan pengurasan
\end{abstract}

\section{PENDAHULUAN}

Dewasa ini banyak sekali orang yang memiliki usaha kolam pemeliharaan ikan, namun banyak sekali kendala yang dihadapi dalam usaha tersebut, misalnya kondisi air yang buruk sehingga banyak sekali ikan yang mati sebelum dipanen. Untuk beberapa jenis ikan tertentu seperti ikan koki memerlukan kondisi air yang jernih untuk dapat hidup. Untuk itu kondi air kolam yang jernih harus tetap dijaga. Namun untuk menjaga kondisi air kolam agar tetap jernih diperlukan pengawasan yang intensif. Untuk memudahkan hal tersebut, diperlukan suatu sistem yang mampu mengontrol sirkulasi air secara otomatis. Sehingga apabila kondisi air keruh, maka sistem tersebut dapat langsung secara otomatis melakukan penggantian air kolam yang keruh dengan air bersih. Sedangkan untuk mengetahui kondisi kekeruhan air digunakan sensor kekeruhan cairan. Pada penelitian ini akan dilakukan pembuatan sensor kekeruhan cairan menggunakan LDR (Light Dependent Resistor). Parameter yang yang harus diketahu jika menggunakan sensor LDR adalah besarnya tegangan yang dihasilkan oleh sensor LDR, posisi pemasangan sensor, kadar kekeruhan air, dan noise. Oleh sebab itu sensor akan diletakkan di dalam posisi yang seminimal mungkin bebas dari gangguan (noise).

Dengan pembuatan sistem kontrol sirkulasi dan deteksi kekeruhan cairan menggunakan sensor LDR, dapat memberikan kemudahan untuk mendeteksi kondisi air kolam pada saat itu. Data yang berasal dari sensor diolah mikrokontroler dan dihitung menggunakan logika fuzzy untuk menentukan kondisi air keruh, sedang dan jernih yang ditampilkan pada LCD. Selanjutnya mikrokontroler memberikan instruksi pada katup yang terdapat pada kolam/aquarium untuk membuka atau menutup untuk melakukan proses sirkulasi air.

Hasil yang telah diperoleh dari percobaan dengan menggunakan aquarium ukuran 30x20x30 Cm, sample air yang digunakan adalah air jernih dan diberi noda untuk mendapatkan 3 kondisi diatas yaitu apabila kondisi air keruh proses pengurasan dan pergantian air dilakukan 3 kali lebih, kondisi sedang dilakukan antara 1 sampai 2 kali, kondisi jernih tidak dilakukan pengurasan dan pergantian air. 


\section{LANDASAN TEORI}

Pada bagian ini akan dijelaskan teori-teori yang berhubungan dengan peralatan yang telah dibuat dan terpakai pada sistem yang terdiri dari mikrokontroer AVR, LDR (Ligh Dependent Resistor), dan logika fuzzy.

\subsection{Mikrokontroler AVR}

Pada [1][2] dijelaskan bahwa AVR merupakan seri mikrokontroller CMOS 8-bit buatan Atmel, berbasis arsitektur RISC (Reduced Instruction Set Computer). Hampir semua instruksi dieksekusi dalam satu siklus clock. AVR mempunyai 32 register general-purpose, timer/counter fleksibel dengan mode compare, interupt internal dan eksternal, serial UART, programmable Watchdog Timer, dan mode power saving. Beberapa diantaranya mempunyai ADC dan PWM internal. AVR juga mempunyai In-System Programmable Flash on-chip yang mengijinkan memori program untuk diprogram ulang dalam sistem menggunakan hubungan serial SPI.

\subsection{LDR (Light Dependent Resistor)}

LDR atau light Dependent Resistor [3] terdiri dari sebuah cakram semikonduktor yang mempunyai dua buah elektroda pada permukaannya. LDR adalah salah satu jenis resistor yang nilai hambatannya dipengaruhi oleh cahaya yang diterimanya. Pada saat gelap, bahan dari cakram tersebut menghasilkan elektron bebas dengan jumlah yang relatif kecil. Sehingga hanya ada sedikit elektron untuk mengangkut muatan elektrik. Artinya LDR akan mempunyai hambatan yang sangat besar saat tak ada cahaya yang mengenainya (gelap). Dalam kondisi ini hambatan LDR, mampu mencapai $1 \mathrm{M}$ ohm. Pada saat cahaya terang, ada lebih banyak elektron yang lepas dari atom bahan semikonduktor tersebut. Sehingga akan ada lebih banyak elektron untuk mengangkut muatan elektrik. Artinya saat terkena sinar, hambatan LDR akan turun secara drastis hingga nilai beberapa puluh ohm saja. Dalam aplikasi, dianjurkan untuk mengukur nilai Rmax dan Rmin dari LDR.

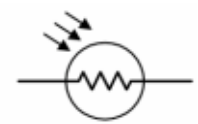

Gambar 1. Simbol LDR

\section{3 logika fuzzy}

Pengendali logika fuzzy menyediakan piranti yang mampu mengubah strategi control linguistic yang diturunkan dari cara berpikir seorang ahli menjadi strategi kontrol otomatis. Struktur sederhana dari pengendali logika fuzzy secara umum disebutkan pada referensi [4][5][6] terdiri dari:

1. Fuzzifikasi

2. Evaluasi Aturan (rule)

3. Defuzzyfikasi

\subsubsection{Fuzzyfikasi}

Proses ini berfungsi untuk merubah suatu besaran analog menjadi fuzzy input. Secara diagram blok dapat dilihat pada gambar 2. Prosesnya adalah sebagai berikut: suatu besaran analog dimasukkan sebagai input (crisp input), lalu crisp input dimasukkan pada batas scope/domain sehingga crisp input dapat dinyatakan dengan label (dingin, panas, cepat, dll) dari membership function. Membership function ini biasanya dinamakan membership function input. Dari membership function biasa diketahui jumlah degree of membership function. 


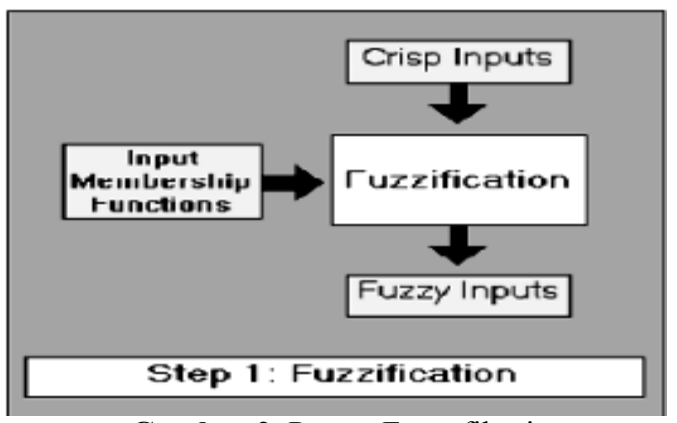

Gambar 2. Proses Fuzzyfikasi

\subsubsection{Evaluasi Aturan}

Proses ini berfungsi untuk untuk mencari suatu nilai fuzzy output dari fuzzy input. Proses dari rule evaluation adalah suatu nilai fuzzy input yang berasal dari proses fuzzifikasi kemudian dimasukkan kedalam sebuah rule yang telah dibuat untuk dijadikan sebuah fuzzy output. Gambar diagram blok dari rule evaluation dapat dilihat pada gambar 3 .

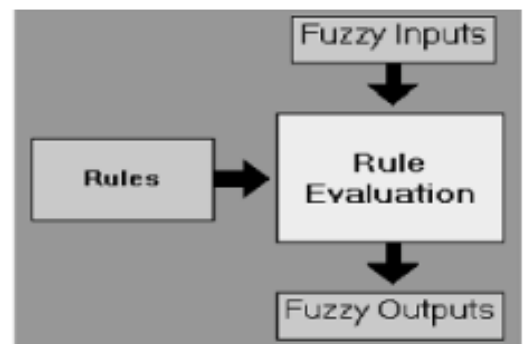

Gambar 3. Diagram Blok Proses Rule Evaluation

Rule evaluation merupakan bagian utama dari fuzzy, karena pada rule evaluation yang menentukan karakteristik dari sistem. Pembuatan rule evaluation yang tidak sesuai akan mengakibatkan respon dari sistem tidak sesuai. Format dari rule adalah sebagai berikut:

If antecedent 1 operator antecendent2

then consequent1 operator consequent2

\subsubsection{Defuzzyfikasi}

Proses ini berfungsi untuk menentukan suatu nilai crisp output. Prosesnya ditunjukan pada gambar 3. suatu nilai fuzzy output yang berasal dari rule evaluation diambil kemudian dimasukkan kedalam suatu membership function output.

\section{METODOLOGI}

Dalam pembuatan sistem dibutuhkan pembuatan hardware dan software diantaranya adalah pembuatan rangkaian mikrokontroler, rangkaian interface LCD, rangkaian sensor LDR, pemrograman pada mikrokontroler untuk pembacaan sensor dan komunikasi serial.

\subsection{Perancangan Sistem}

Pada gambar 4 merupakan blok diagram dari sistem kontrol sirkulasi dan deteksi kekeruhan air yang telah dibuat. Ketika peralatan ini bekerja, kedua sensor akan mulai membaca kondisi air, output dari sensor berupa sinyal analog masuk ke dalam blok ADC untuk diubah menjadi sinyal digital agar dapat diproses oleh mikrkontroler. Pada sistem digunakan ADC internal yang sudah terdapat di dalam mikrokontroler. 


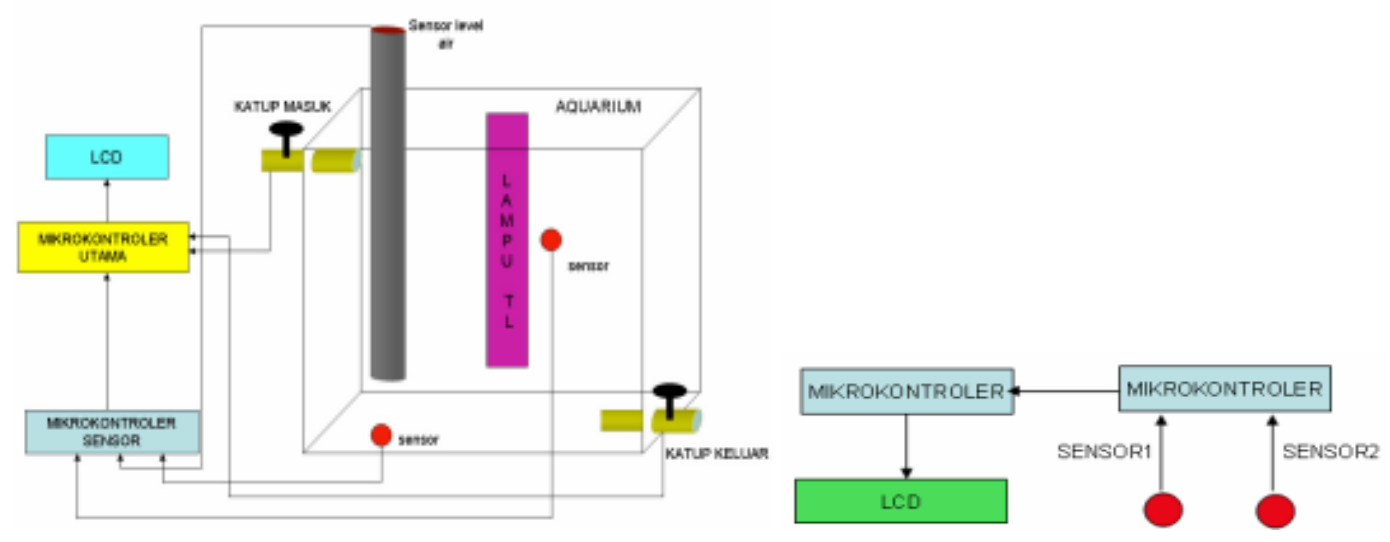

Gambar 4. Blok Diagram Sistem

Setelah itu data tadi akan diproses oleh mikrokontroler dan dihitung menggunakan logika fuzzy, apabila kondisi air pada saat itu keruh, maka mikrokontroler akan menampilkan tulisan "KONDISI KERUH" pada tampilan LCD, apabila kondisi air pada saat itu sedang, maka mikrokontroler akan menampilkan tulisan "KONDISI SEDANG" pada tampilan LCD dan apabila kondisi air pada saat itu jernih, maka mikrokontroler akan menamppilkan tulisan "KONDISI JERNIH" pada tampilan LCD. Selain itu apabila kondisi air keruh dan sedang mikrokontroler juga akan mengirimkan sinyal kepada system control katup untuk menguras aquarium.

\subsection{Perancangan dan Pembuatan Perangkat Keras}

Perancangan perangkat keras menggunakan ATmega162 sebagai mikrokontroler utama dan ATmega8535 sebagai mikrokontroler untuk sensor. Sebagai sarana untuk menampilkan kondisi air digunakan LCD 16x2, sedangkan komunikasi antar kedua mikrokontroler menggunakan komunikasi serial. Sensor kekeruhan dibuat dari aplikasi LDR (Light Dependent Resistor), sedangkan untuk mengkoversi tegangan output dari LDR digunakan ADC internal dari ATmega8535.

\subsubsection{Rangkaian Sensor}

Sensor kekeruhan ini disusun dari gabungan antara LDR dan resistor 1K ohm. Rangkaian ini diberi catu daya $+5 \mathrm{~V}$ sebagai tegangan masukan untuk LDR. Sedangkan tegangan output dari sensor (Vout) akan menjadi masukan bagi mikrokkontroler pada PORTA.0 dan PORTA.1 yang merupakan port ADC internal dari mikrokontroler Atmega8535. Sensor ini akan mendeteksi perubahan kondisi air dengan menangkap intensitas cahaya yang dipancarkan oleh lampu penerang.

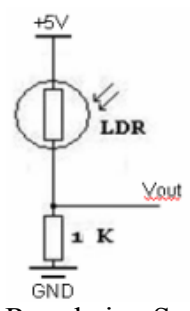

Gambar 5. Rangkaian Sensor LDR

\subsubsection{Rangkaian interface LCD}

LCD yang digunakan adalah LCD 16x2 yang mampu menampilkan 16 karakter perbaris dan mempunyai ROM pembangkit karakter sebanyak 192 tipe karakter dengan font $5 \times 7$ dot matrik. Untuk rangkaian interfacing LCD tidak memerlukan komponen pendukung. 


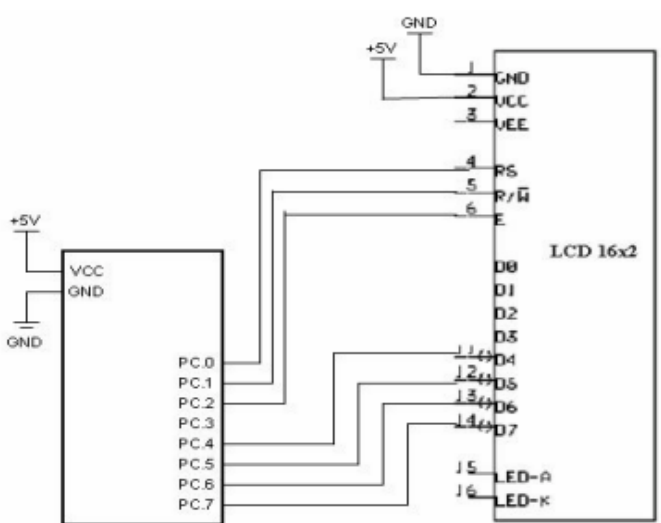

Gambar 6. Konfigurasi Rangkaian LCD

Pada LCD terdapat 8 jalur data yaitu pada kaki 7 sampai 14 dimana terdiri dari 4 bit low dan 4 bit high yang digunakan pada sistem ini hanya 4 bit low saja yaitu kaki 11 sampai 14 saja, karena karakter yang ditampilkan hanya sedikit. Konfigurasi pin LCD pada mikrokontroler ATmega162 menggunakan Port C.

\subsubsection{Rangkaian Mikrokontroler}

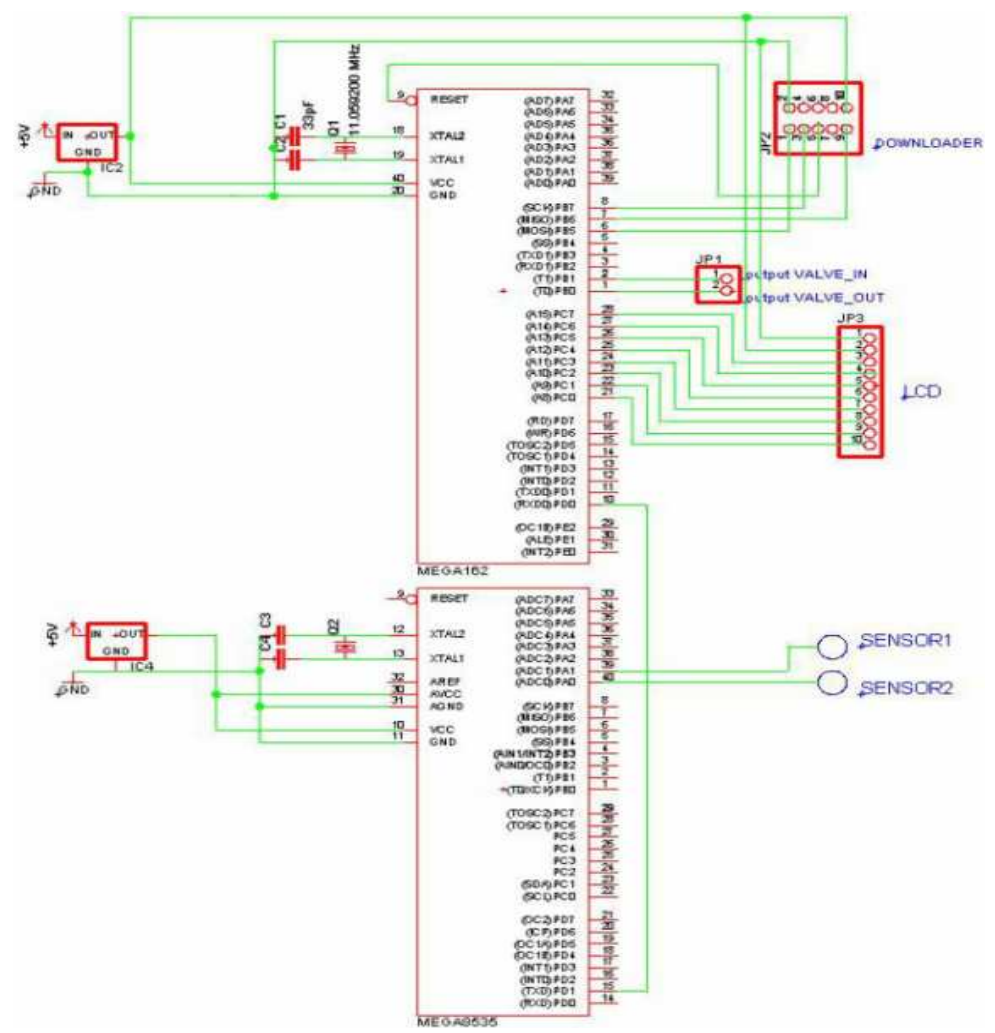

Gambar 7. Rangkaian Mikrokontroler

\subsection{Perancangan Dan Pembuatan Perangkat Lunak}

Perangkat lunak digunakan sebagai protokol antara mikrokontroler dengan LCD dan sensor LDR juga komunikasi antara mikrokontroler. Selain pada [7][8] program dapat juga digunakan untuk mengolah data dari masukan berupa sensor dan mengendalikan keluaran. 


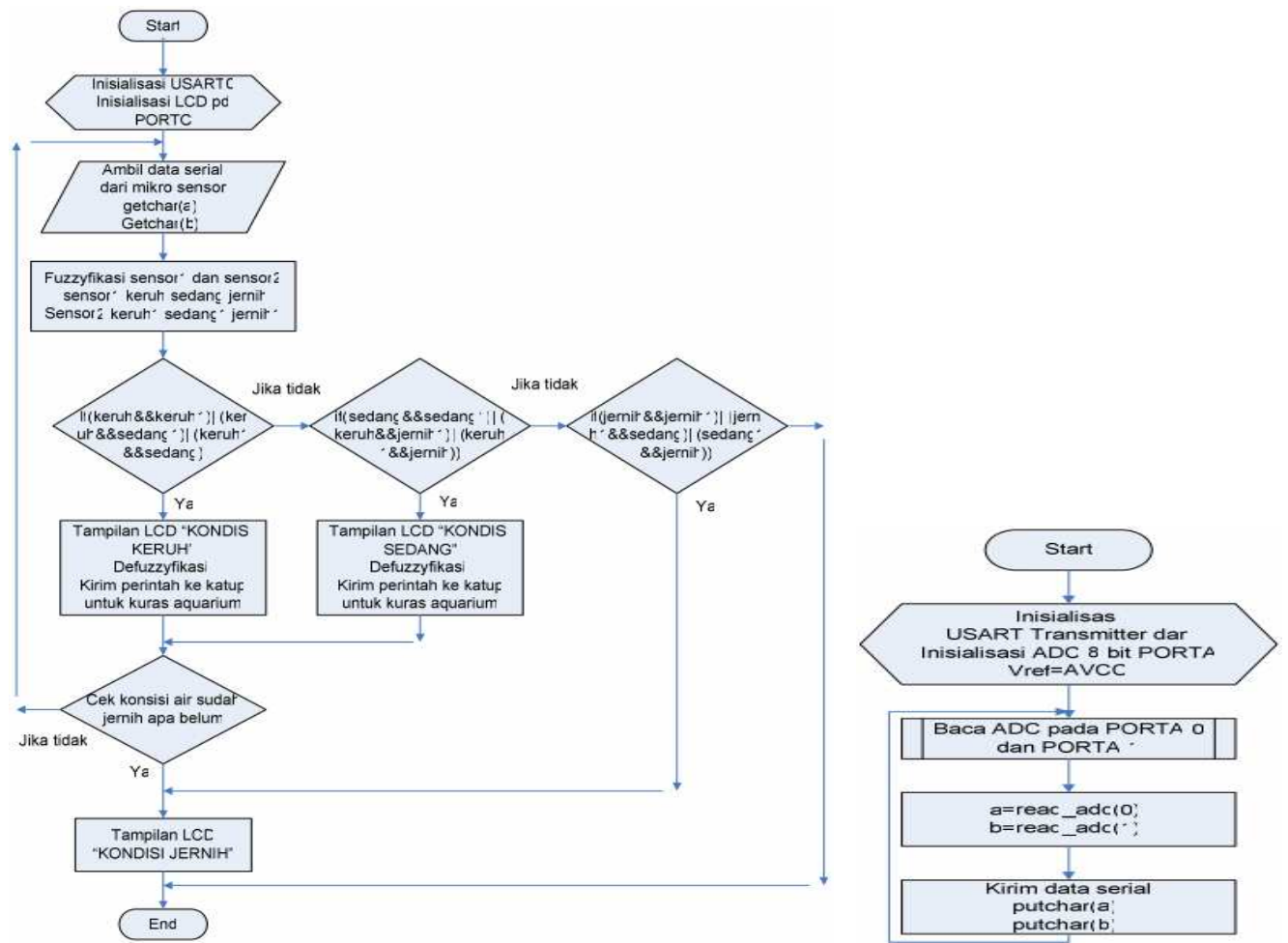

(a) Flowchart Program Mikrokontroler Utama

(b) Flowchart Program Pembacaan Sensor

Gambar 8. Flowchart sistem

Pada gambar 8b. program dalam bahasa $\mathrm{C}$ ini terlebih dahulu dilakukan inisialisasi USART sebagai transmitter untuk komunikasi serial antar mikrokontroler. Setelah itu dilakukan inisialisasi ADC internal pada mikrokontroler ATmega8535. Selanjutnya mikrokontroler akan mengecek data hasil konversi tegangan analog dari sensor1 dan sensor2 pada PORTA.0 dan PORTA.1 yang diinisialisasikan sebagai read_adc(0) dan read_adc(1). Kemudian mikrokontroler akan mengirim data berupa karakter a untuk hasil konversi pada read_adc(0) dan karakter b untuk hasil konversi pada read_adc(1) kepada mikrokontroler utama (Atmega162). dengan perintah putchar(a) dan putchar(b).

Pogram pada mikrokontroler utama diperlihatkan pada gambar 8a. Pada program ini terlebih dahulu diisialisasikan USART sebagai receiver untuk komunikasi serial antar mikrokontroler. Setelah tu inisialisasi LCD sebagai tampilan pada PORTC. Proses selanjutnya dalah mengambil data serial dari sensor lalu dilanjutkan dengan proses fuzzyfikasi sensor. Setelah itu dicek sesuai dengan rule yang dibuat :

1. if sensor1 keruh and sensor2 keruh then krh.

2. if sensor 1 sedang and sensor 2 keruh then krh.

3. if sensor1 keruh and sensor 2 sedang then $\mathrm{krh}$.

5. if sensor 1 jernih then sensor 2 keruh then sdg.

7. if sensor 1 jernih and sensor 2 jernih then jnh.

9. if sensor 1 sedang and sensor 2 jernih then jnh.

4. if sensor 1 sedang and sensor2 sedang then sdg.

6. if snsor 1 keruh then sensor2 jernih then sdg.

8. if sensor 1 jernih sdg sensor 2 sedang then jnh.

Tabel 1. Rule Sistem

\begin{tabular}{|c|c|c|c|}
\hline \multirow[t]{2}{*}{ Sensor 2} & \multicolumn{3}{|c|}{ Sensor 1} \\
\hline & keruh & sedang & jernih \\
\hline keruh & krh & $\mathrm{krh}$ & sdg \\
\hline sedang & krh & sdg & jnh \\
\hline jernuh & sdg & jnh & jnh \\
\hline
\end{tabular}

Keterangan: $\quad \mathrm{krh}=$ kondisi air keruh $\quad \mathrm{sdg}=$ kondisi air sedang $\quad \mathrm{jnh}=$ kondisi air jernih

Apabila diketahui saat itu kondisi air keruh, maka mikrokontroler utama akan mengirimkan perintah kepada katup keluar dan masuk untuk melakukan pengurasan aquarium sampai air pada aquarium jernih, selain itu mikrokontroler utama juga akan menampilkan data jika kondisi aquarium pada saat itu keruh pada LCD. Begitu juga apabila kondisi air pada saat itu sedang, maka mikrokontroler utama juga akan mengirimkan perintah pngurasan untuk mengatur katup masuk dan keluar 
dengan frekuwensi pengurasan tidak sebanyak saat kondisi air keruh, dan menampilkan kondisi air pada saat itu sedang pada tampilan LCD. Sedangkan apabila kondisi air pada saat itu jernih, maka mikrokontroler utama hanya akan menampilkan bahwa kondisi air pada saat itu jernih pada tampilan LCD.

\section{PENGUJIAN DAN ANALISA}

\subsection{Pengujian Sensor}

Pengujian ini dilakukan untuk mengetahui apakah sensor yang digunakan untuk membaca kondisi air pada aqurium dapat berjalan dengan baik. Pengujian dilakukan dengan menghubungkan sensor pada mikrokontroller. Sensor ini terdiri dari dua buah LDR dan resistor. Pengujian dilakukan dengan mengamati data hasil konversi ADC internal pada mikrokontroler dari output tegangan LDR. Bagian listing program konversi $\mathrm{ADC}$ data dari sensor sebagai berikut :

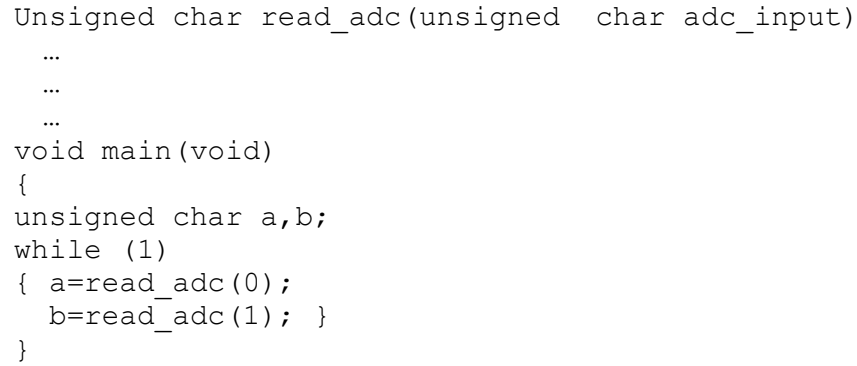

Berdasarkan program di atas maka diperoleh data Rasio hasil konversi sebagai berikut:

Tabel 2. Pengujian Pembacaan Sensor

\begin{tabular}{|c|c|c|c|}
\hline Pembacaan Data Sensor 1 & Vout (volt) & Pembacaan Data Sensor 2 & Vout (volt) \\
\hline 81 & 1.58 & 74 & 1.45 \\
\hline 58 & 1.13 & 73 & 1.43 \\
\hline 32 & 0.62 & 69 & 1.35 \\
\hline 28 & 0.54 & 46 & 0.9 \\
\hline 25 & 0.49 & 33 & 0.64 \\
\hline
\end{tabular}

\subsection{Pengujian Sistem Keseluruhan} berikut:

Dari hasil pengujian kerja sistem diperoleh data kondisi air berdasarkan pembacaan sensor sebagai

\begin{tabular}{|c|c|c|c|c|}
\hline $\begin{array}{c}\text { Pembacaan Data } \\
\text { Sensor } 1\end{array}$ & Vout (volt) & $\begin{array}{c}\text { Pembacaan Data } \\
\text { Sensor } 2\end{array}$ & Vout (volt) & Kondisi Air \\
\hline 81 & 1.58 & 74 & 1.45 & jernih \\
\hline 78 & 1.52 & 66 & 1.29 & jernih \\
\hline 58 & 1.13 & 46 & 0.9 & sedang \\
\hline 32 & 0.62 & 33 & 0.64 & sedang \\
\hline 25 & 0.49 & 69 & 1.35 & sedang \\
\hline 25 & 0.49 & 73 & 1.43 & sedang \\
\hline 28 & 0.54 & 19 & 0.37 & keruh \\
\hline 23 & 0.39 & 26 & 0.5 & keruh \\
\hline 22 & 0.43 & 11 & 0.21 & keruh \\
\hline 11 & 0.21 & 9 & 0.17 & keruh \\
\hline
\end{tabular}

Parameter dari kekeruhan air berdasarkan dari pembatasan pembacaan sensor pada proses fuzzifikasi sensor seperti dibawah ini: 


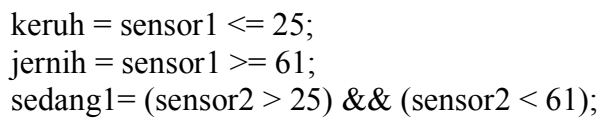

sedang $=($ sensor $1>25) \& \&($ sensor $1<61)$;

keruh1 $=$ sensor $2<=25$;

jernih1 $=$ sensor $2>=61$;

Adapun tampilan dari kurvanya adalah sebagai berikut:

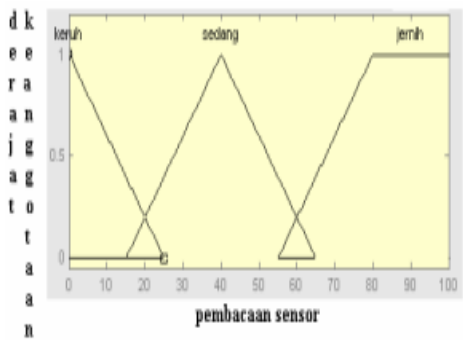

(a)

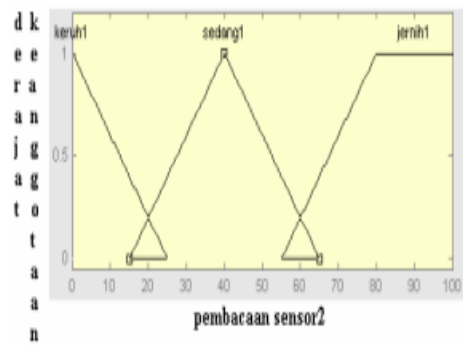

(b)

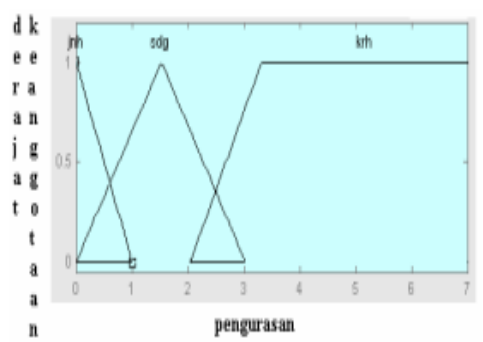

(c)

Gambar 10. (a) dan (b) Kurva Fungsi Keanggotaan Sensor, (c) Fungsi Keanggotaan Output

Dari hasil pengujian pengurasan pada saat kondisi air jernih, sedang dan keruh diperoleh data seperti ditunjukkan pada tabel 4.

Tabel 4. Banyaknya Pengurasan Berdasarkan Kondisi Air

\begin{tabular}{|c|c|}
\hline Kondisi Air & Banyaknya Pengurasan \\
\hline jernih & 0 kali \\
\hline sedang & 1 sampai 2 kali \\
\hline keruh & $=>3$ kali \\
\hline
\end{tabular}

\section{KESIMPULAN}

Dari hasil pengujian sistem sirkulasi dan deteksi kekeruhan air yang telah dibuat dapat ditarik kesimpulan bahwa :

1. Hasil yang didapatkan dari kerja sistem yang dibuat sesuai dengan rule yang ditentukan (tabel.1).

2. Pada proses fuzzifikasi sensor didapatkan parameter untuk kondisi air jernih adalah lebih dari sama dengan 61, kondisi sedang lebih dari 25 dan kurang dari 61, sedangkan untuk kondisi keruh adalah kurang sama dengan 25.

3. Respon kontrol pengurasan pada kondisi air sedang dilakukan 1 sampai 2 kali, kondisi air keruh dilakukan sebanyak 3 kali lebih hingga air terdeteksi kondisinya jernih dan pada kondisi jernih tidak dilakukan pengurasan dan pergantian (sirkulasi) air.

\section{REFERENSI}

[1]. AVR 8-bit Atmega8535 200820 mei www.atmel.com/dyn/resources/prod_documents/doc2502.pdf

[2]. Atmega162 $\quad$ Summary $\quad 2008 \quad 25 \quad$ mei http://www.atmel.com/dyn/products/product_card.asp?part_id=2023/25135.pdf

[3]. LDR 2008 mei 5 http://elkaubisa.blogspot.com/2008/04/light-dependent-resistor-ldr.html

[4]. Kuswadi, Son. Pengantar Pengendali Cerdas di Politeknik, pebruari 1999.

[5]. S. Marsh et al., Fuzzy Logic Education Program, Center of Emerging Computer Technologies, Motorola Inc., 1992

[6]. Tim IE \& Purwahyudi I, 200815 mei , AN16-How 2 Use DT-51 PetraFuz, http://www.innovativeelectronics.com

[7]. Heryanto Ary \& Adi Wisnu, 2008, Pemrograman Bahasa C untuk Mikrokontroler ATMEGA8535, Yogyakarta: Penerbit Andi.

[8]. Barnett, Cox \& O'Cull, 2007. Embedded C Programming and the Atmel AVR, 2e, Kanada: Delmar Learning. 